\title{
augusto ROA bastos e a NarRativa paraguaia atual *
}

\author{
Rubén Bareiro Saguler **
}

Augusto Roa Bastos é considerado, com justiça, a figura central da atual narrativa paraguaia e uma das vozes mais qualificadas e originais da latino-americana.

Para compreender o lugar e a importância do autor no marco literário do scu país, é necessário apelar a um conjunto de elementos que desenham i problemática trajetória de uma literatura profundamente marcada pelo cramático signo da história.

A literatura paraguaia está selada por uma série de problemas capitais e complexos. Problemas que explicam, em certa medida o seu desconhecimento por parte inclusive de tratadistas e antólogos que, sem atrever-se a incursionar, limitam-se a aplicar-lhe o rótulo de "terra incógnita".

Para compreender esta problemática é necessário remontar o rio de sua história e situar a sua escondida presença americana. Zona mediterrânea, reduzida da Província Gigante das Indias à "pequeña isla rodeada de tierra", como a chama Roa Bastos. País mediterrâneo, onde, por uma extensão de $407.000 \mathrm{~km} 2$, a população não excede os dois milhões e meio de habitantes, à qual se devem somar cerca de 900.000 emigrados. Estes dados geo-políticos têm grande importância, pois são os sintomas do espírito de frustraçāo, de encerramento criado no país. Além disso, a escassa densidade demográfica c. o exílio influem na cultura em diversos pontos: escassa difusão num mercado reduzido, fuga de cérebros, desterro de intelectuais e artistas. 0 encerramento, marcado desde o começo da colônia pela ausência de metais preciosos, colocou a regiāo fora das rotas principais da conquista, desde as origens, quando os europeus compreenderam que era impossível chegar às terras do ouro e da prata, por causa do temido e inóspito Chaco Boreal. Desde

- Tradugāo do espanhol por Terumi Koto, Auxtllar de Ensino de Íngua e Literatura Espanhola no Departamento de Letras Estrangeiras Modernas da Unlversidade Federal do Paraná.

** Rubén Bareiro Saguier. Além de poemas (Biografia de ausente, Alcor, Assunção, 1964), contos (Ojo por diente, Monte Avila, Caracas, 1972; Pacte du sang, Le Cerf Pąris, 1971) e critica literária (Cuento y novela, El Arte, Assunçāo, 1960; Panorama de la Literatura Paraguaya in v. III de Panorama das Literaturas de America, Ed. de Joaquim de Carvalho, Coimbra, 1959), publicou mals de cinquenta artigos sobre Literatura Hispano-Americana. Atualmente 6 Maitre de Conférence Associé na Université de Paris VIII.

Letros, Curitiba (25) : $335-346$, jul. 1976 
entāo, o Paraguai ficou relegado; era a zona pobre, a periferia do Vice- reinado do Peru. Isto criou o primeiro círculo de isolamento, e em contrapartida, ajudou a configurar muito cedo a nacionalidade, ao facilitar a mistura generalizada de elementos étnicos - indigena e espanhol - e explicar o surgimento de uma série de fatores históricos configurativos de um grupo humano com caracteres de naçāo. zeloso de suas tradições e de sua autonomia. Este fator positivo de integração cstabelece, contraditoriamente, um isolamento pernicioso pela sua impcrmeabilidade.

$\mathrm{O}$ isolamento que no século XIX adquire formas de encerramento carcerário sob a ditadura do $\mathrm{Dr}$. José Gaspar Rodriguez de Francia; a pobreza da regiāo c a guerra de quase total extermínio - entre 1864 e 1870 o país enfrenta o Brasil, a Argentina e o Uruguai - sāo os principais fatores adversos que explicam o tardio derpertar da literatura no Paraguai, comparado com $c$ resto do continente. Entre estas causas sócio-históricas cabe mencionar a política interna, que influi poderosa e negativamente na ação cultural: a falta de libcrdade por um lado, a injustiça social por outro, criam um esmagador sentimento de frustração coletiva. A maior parte da literatura paraguaia foi escrita no exílio, e a que nasce no pais traz também o signo imposto riclo temor. Uma obra representa não somente o que diz, mas também o que deixa de dizer.

Entre os elementos formativos da nacionalidade, um dos principais é a conservação, no coração materno, da língua aborigine, o guarani, com o seu doce ritmo. De fato, a māe índia, encarregada da educaçāo do filho mestiço. ensinou-lhe a falar em guarani; assim, a lingua da terra perpetuou-se de forma espontânea ao lado da fala culta e imperial do conquistador. $\mathrm{Na}$ maioria dos casos, o castelhano é aprendido pela primeira vez na escola, ccmo segundo língua, sobretudo no campo. Esta permanência tenaz determina um fenômeno sócio-cultural único na América Latina: o bilingüísmo. 1 Ao mesmo tempo que afirma a nacionalidade, o bilingüismo aumenta o isolamento cultural e cria alguns problemas graves para o narrador. Em primeiro lugar, dificulta a expressāo do diálogo: as obras estão escritas em espanhol, mas as personagens pensam e falam em guarani. Sendo as estruturas de ambos idiomas totalmente diferentes, convivem em contraposição destruiciora. sem conseguirem harmonizar-se na obra. O caráter quase exclusivamente oral da literatura oborígine e a diferença fundamental de ambas as linguas impedem as letras paraguaias de aproveitarem a dupla tradição cultural. O presente artigo estudará em que medida a obra de Roa Bastos constitui uma exceçāo no sentido do aproveitamento dos esquemas internos do guarani na narrativa.

Outro problema de ordem material é a falta de meios, que se traduz na escassez de ediçāo no Paraguai (ausência de estímulos; a publicaçāo por conta do autor custa muito caro e quase não existe a empresa editorial).

1 De acordo com o censo de 1962, a porcentagem linguística no Paraguai é a seguinte: monolíngues guaranf, $45 \%$; monolinglies espanhol, $6 \%$; bilingiles, $49 \%$. 
Assim, a obra fragmentária dos escritores se perde no passar efêmero do jornal ou da revista de cultura, cuja edição constitui uma tarefa heróica. Por tudo isso, e por outras razöes relacionadas com a falta de incentivo, a literatura é considerada no Paraguai como atividade marginal, secundária. passageira, que se pratica ao lado de outras mais lucrativas, ou à sombra de profissōes "honrosas". E possivel que o tardio aparecimento do romance tenha algo a ver com o caráter marginal que lembra o trabalho literário em geral; o cultivo da poesia, pela sua brevidade, cabe melhor dentro das possibilidades materiais, no que concerne d̀ elaboração e à publicação.

Por volta de 1935 produz-se uma ruptura. De fato, a Guerra do Chaco (1932-1935), entre Bolivia e Paraguai (uma velha questão de limites adquire sangrenta atualidade nos momentos em que companhias petroleiras rivais disputam entre si a exploração nessa afastada regiāo do continente), acarreta uma mudança nas estruturas mentais. $O$ país e a literatura entram num processo que podemos chamar de modernizaçāo. Até os anos 35/40 a narrativa se manifestava em expressões de marcado estilo costumbrista, num tom de narcisismo autocomplacente. A crítica paraguaia assinala recentemente essas limitaçōes, aponta as carências, sem questionar sobre as causas profundas. Para compreendê-las, considero necessário remeter o fato literário ao processo da produção econômica e ao desenvolvimento sócio-político do pais.

Até a Guerra do Chaco, a sociedade paraguaia conserva uma estrutura primitiva, agro-pecuária. No aspecto político, essa estrutura tem como marco paralelo um esquema liberal e. no econômico, uma forma de "laiserferismo". Na prática uma certa bonomia paternalista - não excluindo a crueldade nas lutas de fraçōes rivais ou "revoluciones" - traduz uma ideologia liberal da burguesia do século XIX, com os valores ideais de 1789, degradados na realidade histórica. A ideologia do grupo dominante se manifesta na obra dos escritores. Esta visão do mundo se revela por meio de uma narrativa que exalta valores simples, ingênuos, quase arcádicos. A obra passou pcla peneira da dupla degradação goldmaniana para dar uma visão da rcalidade própria da mentalidade de uma sociedade rural e "laiserferista"; uma realidade na qual não aparecem os defeitos nem as falhas sociais e que esconde os conflitos de classe. Literatura de cartão postal, preciosista e amareirada.

Dentro deste marco histórico, a Guerra do Chaco, pois, age como uma sacudidela, como uma reação social. Empresa coletiva, o intercámbio derivado do contato obrigatório serve para revisar esquemas, para remover idéias. Por um lado produz-se o descontentamento da massa alistada na contenda. $\geq$ logo dos heróis militares, os quais dificilmente poderăo voltar a adaptar-se ac ritmo da vida civil (começo da subida do elemento militar, que culmina com o atual providencialismo ditatorial). Por outro lado, no movimentado terreno bëlico, $\mathrm{em}$ meio às penúrias do Chaco, discutem-se e ganham corpo certas idéias de protesto social, estimuladas pela insatisfação. Remoção nas idéias e nas elites. 
No que diz respeito à literatura, as mudanças sensíveís se operam primeiro no campo da poesia, por volta de 1940 (Roa Bastos é um dos promovedores desta renovaçāo poética). Para que aconteça o mesmo na narrativa. têm de passar mais alguns anos. O primeiro a manifestar a visão crítica é Gabriel Casaccia, que com o seu romance "La Babosa", 2 publicado em 1952, produz um escândalo no timorato e reacionário ambiente literário paraguaio.

O Paraguai vivia mais um dos "periodos de paz", sob a autoridade de um dos tantos ditadores militares. Imediatamente acusou-se o romancista de "traidor", "enemigo de la nación", "roedor de los mármoles de la patria", como gosta de chamar a imprensa oficial - inclusive até agora - a qualquer heterodoxo. A razão era simples: todo o esquema descrito acima se desfazia cm pedaços ante a maneira como Casaccia punha a descoberto certas falhas da sociedade e formas de frustraçāo do ser coletivo (especialmente no âmbito da burguesia média, núcleo depositário da ideologia dominante).

No ano seguinte, publica-se El Trueno entre las Hojas, 3 de Augusto Roa Bastos, que reforça a mesma linha de crítica visceral da sociedade, com reação oposicionista, semelhante à descrita. A visão distorcida, ideológica da narrativa anterior tinha impedido mostrar certos aspectos da realidade. No Paraguai, conhecem-se de perto a violência, os crimes horrendos, as violacōes coletivas, as matanças nas "revoluciones", as injustiças de toda espécie, a misćria e suas fealdades. Mas tudo isso sāo probleminhas domésticos, a literatura não tem por que ocupar-se dessas notas dissonantes; nāo há razōes para mostrar publicamente essas cicatrizes vergonhosas. A mudança ideológica impõe aos autores como Casaccia e Roa uma visão distinta da realidade, conflitiva, crítica e violenta.

Augusto Roa Bastos, de infância campesina (toda sua obra guarda a pureza, a força da natureza; cheira à selva, à terra molhada), iniciou-se liierariamente na poesia. O seu primeiro livro narrativo editado é o citado volume de contos, El Trueno entre las Hojas. Lendo-o, pode-se apreciar até que ponto o poeta Roa Bastos continua vivendo no contista. Há páginas inteiras em que se descobre uma cadência, uma cadência ritmica introduzida na prosa. Do ponto de vista expressivo, Roa Bastos apela neste livro ao uso de um expressionismo potente, conseguido mediante profundas incisōes, fortes traços e chocantes oposiçōes sobre uma realidade cujos matizes oscilam entre o branco da inocência e o vermelho sangrento da violência. Conceito essencial este: todos os indices tendem a convertê-lo no verdadeiro código dos contos. Cabe opor a obra de Roa Bastos à do citado Gabriel Casaccia. Este insiste sobre o aspecto da frustraçāo, enquanto que Roa insiste no da violência, neste livro. Caraterística passiva a de Casaccia; essencialmente ativa a de Roa Bastos. Qual é a mensagem implícita em uma e outra obra? Ambos os autores incidem sobre a realidade. Casaccia passivamente, desde o unirerso da pequena ou média burguesia decadente, que é também o seu. A sua visāo do mundo torna-se conflitiva, como conseqüência da descrição de

2 Buenos Aires, Losada, 1952. 322 p.

3 Buenos Aires, Losada, 1953. 255 p. 
um meio deteriorado que traduz quase como cronista. Em Roa Bastos, pelo contrário, existe uma vontade de transformação na base; a sua visão do mundo ć conflitiva na própria base; tem uma sustentação consciente de rebeldia frente às falhas de sua coletividade. Roa o expōe lucidamente:

Ante el espectáculo de los males que afligen a la patria, resulta en verdad difícil mantener una circunspecta mesura artística. Las vocaciones más pacientes se vuelven amargas y. violentas. Sería inútil reclamarles una producción literaria para el simple disfrute estético de minorías privilegiadas. A mi me avergonzaria escribir exclusivamente para minorias cultas y. si estuviesse forzado a hacerlo, emplearia, lo confieso, todos los recursos de mi voluntad para irritarlos y sacarlos de quicio. 4

Isto não quer dizer, de forma alguma, que Roa faça literatura de tese. E por demais bom escritor para adotar fórmulas baratas ou receitas préfabricadas. Trata-se simplesmente de uma busca lúcida contra a podridāo do meio e, longe de cair numa caricatura limitativa, consegue um enfoque múltiplo e totalizador da realidade paraguaia.

Como opera Roa Bastos? Por meio de símbolos. Em El Trueno entre las Hojas o símbolo está apresentado na epigrafe: "El trueno cae y se queda cntre las hojas. Los animales comen las hojas y se ponen violentos. Los horebres comen los animales y se ponen violentos. La tierra se come a los hombres y empieza a rugir como el trueno". Esta belíssima lenda guarani. recuperada por Roa. é a tônica do livro, cuja razāo profunda está explicada por ele quando descreve a atitude de rebeliāo e de agressividade verbal:

\begin{abstract}
Yo soy burgués, o al menos pertenezco por mi extracción a la classe pequeñoburguesa; pero la única posibilidad que tengo de liberarme de ese molde social caduco es sublevándome contra él para acercarme a la masa de los oprimidos. No me puedo jactar de pertenecer a la clase de los opresores: no es un orgullo el serlo, pero tengo que hacer algo para redimirme de su estima y afirmar mi deseo de liberación. 5
\end{abstract}

A frase demonstra as intençōes, ou a tornada de consciência do homem Roa Bastos. A qualidade do livro justifica amplamente o escritor.

o livro comentado é uma simples metáfora, se comparado com a grande parábola que é Hijo de Hombre. 6 Esta parábola tem como centro e razāo cie ser o homem humilde de seu país, é o "hijo de hombre" crucificado diariamente e ao longo do tempo trágico de sua história. A parábola do povo paraguaio subjugado, escarnecido, desterrado, enterrado. Uma das epigrafes do romance cita o versículo XII, do profeta Ezequiel: "Hijo de Hombre, tú habitas en medio de casa rebelde...". E pois a história de suas afliçōes e de seus sofrimentos.

4 Respuesta de Augusto Roa Bastos. Alcor, Asuncíón (2):1, mar. 1955

5 Ibid., p. 1.

6 4. ed. Buenos Aires, Losada, 1971. 281 p. 
Mas é também a parábola de sua luta, da esperança do seu povo, do afã de redençāo - sempre característica ativa - que Roa Bastos deposita na segunda epigrafe do livro, por meio de um fragmento do hino dos mortos dos guaranis: “... He de hacer que la voz vuelva a fluir por los huesos... Y haré que vuelva a encarnarse el habla... Después que se pierda este tiempo y un nuevo tiempo amanezca..." Em declaraçōes feitas posteriormente, Roa Bastos esclarece e amplia as intenções:

La lejania de la patria me impuso al tema de esta novela, tema que había herịdo mi sensibilidad en los largos años de reflexión sobre mi tierra y sus problemas. Siempre que quise recordar y recobrar la imagen esencial de nuestro pueblo me encontré con esa voluntad de resistencia, de persistir a todo trance a pesar de los infortunios, las vicisitudes en que tan pródiga ha sido nuestra historia. De ahí surgió el motivo inicial que se construyó en núcleo de la temática de Hijo de Hombre, cuyos nueve capítulos no son sino unas tantas variaciones sobre la resistência del hombre, no solamente a la extinción física sino também a la degradación moral. $?$

O tom muda e os indices narrativos tendem a formular um novo código: o da luta e a resistência do povo ante a adversidade. A violência, sem desaparecer totalmente, se aplaca e surgem em seu lugar símbolos de resgate, belíssimos, cheios de poesia, como o do Cristo leproso de Itapé - obra de um entalhador violonista, leproso - que nāo tem acesso à igreja e é venerado pelo povo na intempérie, no alto de uma colina. Esta imagem é de certa maneira representativa, tem uma alta carga de significação, já que Roa Bastos toma como personagem o seu povo, personagem coletivo que vai mudando de rosto no romance, mas não de padecimento. A parábola abrange uma longa trajetória histórica. desde a época do Ditador Francia, até a guerra do Chaco e os acontecimentos políticos posteriores a luta, que por sua vez constituem outros passos em falso no espinhoso caminho da justiça. Assim, vão desfilando cenas da ditadura; uma sublevação campesina; a fuga de um casal do inferno do ervaçal; o presidio por razōes políticas numa ilhota, que por ironia chama-se Penha Formosa; a sede e a morte absurda na Guerra do Chaco, e a impossível reintegraçāo dos ex-combatentes à vida normal. o código do livro está formulado quase no final, pela boca de um dos personagens, que manifesta toda sua carga de indignaçāo, mas também de esperança, com estas palavras:

No pienso en ellos solamente. Pienso en los otros seres como ellos, degradados hasta el último límite de su condición. como si el hombre sufriente y vejado fuera siempre $\mathrm{y}$ en todas partes el único fatalmente inmortal. Alguna salida debe haber en este contrasentido del hombro crucificado por el hombre. Porque de lo contrário sería el caso de pensar que la raza humana está maldita para siempre, que esto es el infierno y que no podemos esperar salvación. Debe haber una salida, porque de lo contrario... 8

73 escritores 3 visiones de la novela. Alcor, Asunclón (41):7, oct. 1966.

8 Hijo de hombre, p. 279. 
Que meios utiliza o autor para unir os episódios dispersos através de um lapso que dura quase um século? Na realidade, importa menos a linha argumental conccbida de uma maneira tradicional do que a história do sofrimento e da ânsia de redenção coletivos, verdadeiros protagonistas e, ao mesmo tempo. fio condutor da narraçāo. A obra mantém uma coerente unidade. As rupturas temporais, que em muitos escritores latino-americanos atuais implicam um desenvolvimento de habilidade técnica, no romance de Roa Bastos estão impostas pelas características da obra, pela longa trajetória. pclo lapso descontínuo através do qual se estende a ação. A estrutura de obra aberta, em Hljo de Hombre, não é, pois, um elemento arbitrário, mas

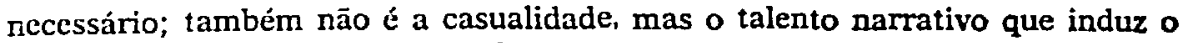
autor a usar as estruturas quebradas no tempo. Tecnicamente, cada uma clas nove partes do livro funciona aparentemente de forma independente, quasc sem conexāo lógica evidente. Mas a existência de um relator comum, Miguel Vera, unido à voz do relator-autor, confere-lhe a unidade externa; a interna é conseguida pelo alento coletivo que impregna o romance.

Ao referir-se à obra de Malraux 9 Lucien Goldmann fala do surgimento (io personagem colctivo, como consequiência de que a ação já não é essencialmente individual e psicológica, mas multidunária e social. Em Hijo de Hombre produz-se um processo dessa natureza. Na trajetória descrita pela ıarração, as individualidades desaparecem e o protagonista è a força coletiva, um alento popular, que $\mathrm{cm}$ cada episódio encontra a expressāo na ação comunitária e na realizaçāo de uma tarefa, que debilita ou borra a presença do personagem individual. Assim Gaspar Mora, Casiano Amoité, Cris!óbal Jara, etc., não sāo senāo acidentes ou facetas do grande personagem que se chama povo-escarnecido-e-em-luta. No contexto dos personagens, não se pode deixar de mencionar a presença constante do anti-herói (o citado jelator Miguel Vera), cuja conduta covarde e condiçāo essencial de indivíduo indeciso e frustrado - o único que está caracterizado com fortes traços psicológicos - pōe um contrapeso, mostra o reverso da medalha: se se tem $\mathrm{em}$ conta o caráter essencial e intencionalmente ativo da literatura de Roa Bastos, este personagem incapaz para a ação, o narrador da grande parte do livro, com o seu relato está criando. em negativo, a ação heróica do personagem coletivo. Anverso que cria o reverso da trama narrativa: recurso técnico magistralmente logrado.

No plano da expressão. Roa Bastos apela para uma linguagem que é o resultado da combinação da fala dircta com locuçōes, fórmulas e expressōes extraidas das entranhas do guarani. Assim, obtem o alento altamente poético que impregna a sua obra narrativa. Roa Bastos tenta desta forma apoderar-se de uma linguagem prọ́pria, que é uma das buscas dos escritores latino- americanos, a fim de definir a sua identidade. Para isso, Roa Bastos recorrc. à fonte da língua aborígine; nāo ao guarani em si - escreve em espa-

9 GOLDMANN, Lucien. Introduction a une étude structurelle des romans do Malraux. In: - Pour une sociologie du roman. Paris, Gallimard, 1964. p. $59-279$. 
nhol - mas ao seu frescor, à força de sua expressão metafórica, como forma de reação contra o idioma imposto pelo conquistador. A quebra do casticismo, mediante a presença interna das estruturas guaranis, torna-se um elemento altamente enriquecedor na prosa de Roa. O próprio autor define o procedimento:

No tomar el castellano y salpicarlo de términos guaranies (que se aclaran en un glosario final o en notas a pie de página), sino malear, trabajar el castellano hasta crear las inflexiones, el tono emocional del idioma vernáculo; porque una cosa es el toque pintoresquista, marcadamente exterior, y otra muy distinta la reconstrucción desde adentro mismo del idioma. ${ }^{10}$

O êxito no domínio desta integração lingüística, que o autor define tão bem, é mais patente em textos posteriores, especialmente na primeira parte do volume de contos Moriencia e, naturalmente, no seu último grande romance Yo el Supremo. 11 As integrações temáticas, sintáticas e inclusive fonéticas, com, base nas estruturas do guarani, foram levadas muito longe nestes livros.

Augusto Roa Bastos abandonou o Paraguai por razões políticas em 1947. Por espaço de longos anos esteve ausente do país. Os quatro livros de contos que publicou entre 1966 e 1969 marcam parcialmente a dolorosa fase de exílio do autor. 12

Um crítico argentino qualificou o narrador desse período com a frase: "paraguayo oporteñado", de alto humor negro, aplicado a um escritor que se reconhece tão enraizadamente ligado a sua terra. A temática dos contos ao exílio vai da fase do desterro rebelde, que descreve a luta para voltar à fátria, a resistência - ativa, na constante mais firme de sua narrativa ¿े fase passiva, na qual as personagens vão perdendo a sua rebeldia, integrando-se ao grande orbe portenho, vencidos pela fatalidade corrosiva do ostracismo. E outros contos, nos quais as personagens e os temas são já nitidamente portenhos, e onde a referência ao Paraguai é apenas uma alusão passageira, ou narrações em que o mesmo desaparece por completo (existe uma série de contos em torno a um personagem tipicamente portenho, "el gordo". Na mesma série é possível apreciar a trajetória citada).

Fiel à sua concepção e prática da obra como uma vivência, Roa Bastos transmuta nesses livros a experiência da violenta desnaturalização. A epígrafe - mais uma vez - de El Baldío explica a nova situação: "... el que abandona su viña la verá morir dentro de sí en baldio, y su vino será amargo..."

Como esses afogados arrastados pelo rio, o narrador vai dando tombos, retido por momentos nas grandes raízes, imerso na correnteza fatal, da qual

10 La pesadilla de un escritor. Siete Dias, Buenos Aires, oct. 1974. p. 26.

11 Moriencia. Caracas, Monte Ávila, 1969. 176 p.; Yo el supremo. Buenos Aires, Siglo XXI, 1974. 467 p.

12 El baldio. Buenos Aires, Losada, 1966. 152 p.; Los pies sobre el agua. Buenos Aires, CEAL, 1967. 160 p.; Madera quemada. Santiago, Ed. Universitária, 1967. 169 p.; Moriencia. 
emerge a cabeça para tratar de absorver o ar da morte-exílio. No nivel mais evidente do significante, pode-se ver uma prova de sua desgarrada angústia na reelaboraçāo de alguns relatos dentro da sucessāo dos citados volumes.

Livros catárticos ou experimentais, chamou-os Roa Bastos com sua proverbial modéstia. Na realidade, sāo muito mais do que isso: contos nos quais vão se provando e decantando novas técnicas, afirmando o instrumento expressivo, que desembocará nessa obra prima que é Yo el Supremo. Nesta trajetória, que une a sua produção anterior com o último romance, existem momentos de alta tensão narrativa, como tantos contos, ou para citar uma porçāo mais ou menos unitária, os cinco relatos que iniciam Moriencia, esboços de capítulos de um romance, que mostram o total domínio que possui Roa Bastos de seus meios e instrumentos expressivos. Não só do manejo das molas da arte literária, mas também da possibilidade de aproveitar a língua aborígine e de integrar o seu ritmo profundo ao espanhol, quebrado ou modificado desde o intimo da fala narrativa.

Todas as possibilidades anotadas foram conseguidas em alto grau no seu romance Yo el Supremo. Cinco anos de intensa elaboraçāo deram como resultado uma obra de grande riqueza, na qual é possível ir descobrindo conotações das mais diversas índoles, infinitos niveis semânticos, onde campeiam a ambiguidade multívoca e desorientadora, a flutuante ironia. a exaltação histórica...

Com este livro Roa Bastos recobra plenamente a sua terra, aprofunda-se nela até a medula, escava a sua história e dá uma visāo prospectiva do seu destino. Tudo isso por meio da figura do Dr. José Gaspar Rodríguez de Francia, Ditador Perpétuo da República do Paraguai entre 1814 e 1840, ano de sua morte. Mas não se trata de uma biografia ou de um romance histórico centrado na época desta original personagem. $O$ autor esclarece-o muito bem:

En la obra de ficción, los hechos históricos, el ascenario mismo de la historia, constituyen el marco de una nueva realidad: la realidad imaginaria. Y esta realidad cristaliza, o mejor dicho, se dinamiza y vivifica en símbolos y en mitos que reflejan otra historia no necesariamente igual o parecida a la que nos repite la historiografia documental. No intenté hacer una biografia novelada del Supremo Dictador. Como personaje histórico, José Gaspar Rodríguez de Francia es un personaje único. No se le puede repetir y menos sustituir por um personaje pretendidamente hecho a su imagen y semejanza, aun cuando fuera en el terreno de la ficción. Aquí únicamente yo podía intentar el desarrollo de una trama imaginaria en torno a un personaje mítico que en la novela ni siquiera tiene nombre; un personaje que ejerce el poder absoluto al servicio de una causa en la cual encarna los intereses y el destino de una colectividad. 13

13 CHaVes, Raquel. Entrevista com Roa Bastos. Diálogo, Asunción, 5 maio 1974. p. 33-7.

Letras, Curitiba (25) : $335-346$, jul. 1976 
A citação dá as chaves do código do romance: as relações entre a ficçāo e a história, entre o personagem histórico e o mito encarnado por esse personagem, vivo e presente na coletividade, ainda hoje, 125 anos depois de sua morte. Isto quer dizer que os valores representados pelo regime nacionalista co Dr. Francia continuam sendo de total atualidade, e constituem um desafio ao leitor contemporâneo - ao paraguaio em especial - obrigado ao vaivém comparativo. A partir da visão de Francia. Roa reinterpreta a história e realiza uma trajetória prospectiva sobre o futuro do país.

E possivel, pois, fazer uma leitura atualizada do romance, através das claves míticas presentes no texto. A denotação textual nos impōe o "leit-motiv" que, de maneira obssessiva. caracteriza toda a atuação de José Gaspar de Francia: a defesa da independência do país (nāo só contra a antiga rnetrópole. Espanha, mas também contra a Argentina e o Brasil do século 19). As conotaçōes intratextuais levam naturalmente a considerar a oposição dc atitudes entre os dois momentos históricos, o de Francia e o atual. Ambos funcionam dentro de um marco ditatorial, mas enquanto o primeiro atua como defensor intransigente da integridade nacional, causa eficiente da Ditadura francista, o regime atual está entregue à penetração dos interesses estrangeiros, conseqüência da corrupção ditatorial. Na primeira folha do painel. a Ditadura instituída oficialmente como regime de governo - apoiada rıuma eleição popular - é justificada pela ameaça exterior; a argumentação ganha pleno sentido e coerência, esteja ou nāo de acordo com ela. Tudo envolto num clima de austeridade, o que reflete no nível verbal do romance. $\mathrm{Na}$ segunda folha, a tirania imperante hoje em dia é negada hipocritamente $\mathrm{e}$ inundada num verborréico discurso, nadando no caldo da desonestidade e da corrupçāo. Anverso e reverso da medalha autocrática. Não se trata de uma interpretaçāo fantasista ou sectária. Existe no texto uma série de índices explícitos que permitem ver a projeção desta leitura $\mathrm{cm}$ linhas paralelas. 0 próprio autor manifesta-o claramente numa declaraçāo:

El desdibujamiento de una línea cronológica en la narración, la abolición de las fronteras de tiempo y espacio fueron los procedimentos que se me impusieron como los más eficaces para no encerrarla en los marcos de una época histórica determinada y trascenderla más vale hacia una significación que pudiera llegar hasta el presente del lector. ${ }^{14}$

A análise do significado - insinuo acima uma leitura possível - não pode ser realizada sem referências à estrutura protéica do livro. Um longo monólogo do Ditador agonizante, misturado com intervençōes do "compilador" (título que se atribui o autor), dão como resultado um texto cheio de sugestōes, em que os níveis semânticos se superpõem e entrecruzam, evitando qualquer classe de caricatura em torno do personagem, apesar da simpatia que o relator possa sentir por ele.

14 RODRIGUEZ ALCALÁ. Beatriz. Yo el supremo visto por su autor y aproximaciones. In: COMENTARIOS sobre Yo el supremo. Asunción, Club del Libro, 1975. p. 25. 
E praticamente impossivel dar conta das infinitas facetas deste livro num panorama suscinto como o presente. Para concluir, só quero acresccntar que Yo el Supremo coloca Augusto Roa Bastos como um dos romancistas mais importantes da atual narrativa latino-americana, ao mostrar um escritor maduro, dono de seus meios expressivos, cheio de uma força tremenda, tanto pelos significados do livro quanto pela riqueza textual, pela polifonia do relato. Roa Bastos, um dos iniciadores ou ofirmadores das renovaçōes da nova narrativa no continente, foi excluído - como Rulfo ou como Arguedas - da montagem publicitária chamada "el boom". A potência da obra, que culmina em Yo el Supremo, impōe, por cima das operaçōes comerciais, um grande escritor.

\section{REFERENGIAS BIBLIOGRAFICAS}

CASACCIA, Gabriel. La babosa. Buenos Aires, Losada, 1952, 322 p.

CHAVES, Raquel. Entrevista com Roa Bastos. Diálogo, Asunción, 5 maio 1974. p. $33-7$.

COMENTARIOS sobre Yo el supremo. Asunción, Club del Libro, 1975. 67 p. GOLDMaNN, Luclen. Pour une sociologie du roman. Paris, Gallimard, 1964. 372 p. ROA BASTOS, Augusto. El baldio. Buenos Aires, Losada, 1966. $152 \mathrm{p}$.

- Hijo de hombre. 4. ed. Buenos Aires, Losada, 1971. $281 \mathrm{p}$.

Madera quemada. Santiago, Ed. Universitária, 1967. 169 p.

Moricncia. Caracas, Monte Avila, 1969. $176 \mathrm{p}$.

La pesadilla de un escritor. Siete Dias, Buenos Aires, oct. 1974. p. 24-6.

Los pies sobre el agua. Buenos Alres, CEAL, 1967. $160 \mathrm{p}$

Respuesta de Augusto Roa Bastos. Alcor, Asunción (2):1-3, mar. 1955.

3 escritores, 3 visiones de la novela. Alcor, Asunción (41):7-9, oct. 1966.

El trueno entre las hojas. Buenos Aires, Losada, 1953. 255 p.

Yo el supremo. Buenos Aires, Siglo XXI, 1974. 467 p.

\section{Resumo}

Augusto Roa Bastos é um dos escritores mais importantes não só da literatura paraguaia como também da latino-americana. Para compreender esta importância é necessário percorrer a trajetória da própria literatura paraguaia, a qual está marcada pelo dramático signo da história.

A configuração da nacionalidade paraguaia está relacionada diretamente com a sua situação geográfica e caracterização econômica, fatores que determinam o isolamento e o sentimento de frustração coletiva no país. Soma-se a isto a política interna no século XIX, que tira dos paraguaios a liberdade e os esmaga com a injustiça social. A grande parte da literatura paraguaia foi escrita no exílio e a produzida no país traz também o signo do temor.

É dentro deste contexto sócio-político-cultural que irrompe a obra de Roa Bastos, precedida por La Babosa, de Gabriel Casaccia. Ambas produzem impacto no timorato ambiente literário do pais, porque pōem à mostra as falhas da sociedade.

Não se trata, entretanto, de uma literatura de tese, mas de uma visão totalizadora da realidade paraguaia, sem que caia em mero documentário. 
O valor literário de Roa Bastos está no manejo dos símbolos e no aproveitamento da tradiçāo cultural e lingüística do guarani, o que dá alento poético a todas suas obras. Ao conseguir harmonizar os recursos do espanhol com os da língua aborígine, Roa Bastos alcança a sua própria identidade como homem paraguaio, ao mesmo tempo que define a literatura de sua pátria e se impōe como um grande escritor.

\section{Resumen}

Augusto Roa Bastos es una de las voces más importantes no sólo de lá literatura paraguaya sino también de la latinoamericana. Para compreender esta importância es necesario recorrer la trayectoria de la propia literatura paraguaya. la cual está marcada por el dramático signo de la historia.

La configuración de la nacionalidaa paraguaya está rclacionada directamente a su situación geográfica y caracterización económica, factores que determinam el aislamiento y el sentimiento de frustración colectiva en el país. Se acrece a csto, la politica interna del siglo XIX que les quita a los faraguayos la libertad y les aplasta con la injusticia social. La gran parte de la literatura parguaya fue escrita en el exilio y la producida dentro del país trae asimismo el signo del temor.

Es dentro de este contexto socio-político-cultural que irrumpe la obra de Roa Bastos, precedida por La Babosa, de Gabriel Casaccia. Las dos producen impacto en el timorato ambiente literário del país, porque ponen a descubierto las fallas de la sociedad.

No se trata, empero, de una literatura de tesis, sino de una visión totalizadora de la realidad paraguaya, sin que resbale en mera descripción documental.

El valor literario de Roa Bastos estã en el manejo de los símbolos y en el aprovechamiento de la tradición cultural y linguiística del guaraní, lo que les da a todas sus obras aliento poético. Al lograr armonizar los recursos del castcllano con los de la lengua aborigen, Roa Bastos consigue su misma identidad como hombre paraguayo a la vez que define la literatura de su patria y se impone como un gran escritor. 